\title{
Volatile organic compounds decomposition using nonthermal plasma coupled with a combination of catalysts
}

\author{
${ }^{1}$ T. Zhu; ${ }^{1}$ Y. D. Wan; ${ }^{2} J . L i ;{ }^{1}$ X. W. He; ${ }^{1}$ D. Y. Xu; ${ }^{1} X$. Q. Shu; ${ }^{2}$ W. J. Liang; ${ }^{2}$ Y. Q. Jin \\ ${ }^{1}$ School of Chemical and Environmental Engineering, China University of Mining and Technology, \\ Beijing, China \\ ${ }^{2}$ College of Environmental and Energy Engineering, Beijing University of Technology, Beijing, China
}

Received 21 June 2010; $\quad$ revised 17 March 2011; accepted 25 April 2011; available online 1 June 2011

\begin{abstract}
A series of experiments were performed for toluene decomposition from a gaseous influent at normal temperature and atmospheric pressure by nonthermal plasma coupled with a combination of catalysts technology. Nonthermal plasma was generated by dielectric barrier discharge. $\gamma-\mathrm{Al}_{2} \mathrm{O}_{3}$ was used to be a sorbent and a catalyst carrier. Nanocatalysts were $\mathrm{MnO}_{2} / \gamma-\mathrm{Al}_{2} \mathrm{O}_{3}$ coupled with modified ferroelectric of nano- $\mathrm{Ba}_{0.8} \mathrm{Sr}_{0.2} \mathrm{Zr}_{0.1} \mathrm{Ti}_{0.9} \mathrm{O}_{3} \cdot \gamma-\mathrm{Al}_{2} \mathrm{O}_{3}$ played an important role in prolonging reaction time of nonthermal plasma with volatile organic compounds molecules. $\mathrm{MnO}_{2} / \gamma-\mathrm{Al}_{2} \mathrm{O}_{3}$ has an advantage for ozone removal, while nano- $\mathrm{Ba}_{0.8} \mathrm{Sr}_{0.2} \mathrm{Zr}_{0.1} \mathrm{Ti}_{0.9} \mathrm{O}_{3}$ is a kind of good ferroelectric material for improving energy efficiency. Thus these packed materials were incorporated together to strengthen nonthermal plasma power for volatile organic compounds decomposition. The results showed the synergistic technology resulted in greater enhancement of toluene removal and energy efficiencies and a better inhibition for ozone formation in the gas exhaust. Based on the data analysis of the Fourier transforms infrared spectrum, the reaction process of toluene decomposition and the mechanism of synergistic effect are discussed. The results showed in a complex oxidation mechanism of toluene via several pathways, producing either ringretaining or ringopening products. The final products were carbon dioxide and water.
\end{abstract}

Keywords: Energy efficiency; Ferroelectric; Synergistic effect; Toluene

\section{INTRODUCTION}

Volatile organic compounds (VOCs) are triggering serious environmental problems such as stratospheric ozone depletion and photochemical smog, etc. Control of VOCs in the atmosphere is a major environmental problem now and attracts more and more researchers' attentions (Futamura et al., 1997; Muhamad et al., 2000; Gal et al., 2003; Magureanu et al., 2005; Malik et al., 2005; Kim, 2006; Magureanu et al., 2007; Juang et al., 2009a; b; Zhu et al., 2009a). As one of the typical VOCs, toluene effluents came from many industries, including paints, paint thinners, fingernail polish, lacquers, adhesives, rubber and some print and leather tanning processes. Several strategies have been identified in order to reduce toluene presence in civil and industrial emissions due to its noxiousness. As an emerging technology for environmental protection, Nonthermal plasma (NTP) has been subjected to extensive researches over the past 20 years (Mizuno et al., 1986;

《*Corresponding Author Email: bamboozt@cumtb.edu.cn Tel./Fax: +861 062331360
Masuda et al., 1988; Chang et al., 1991; Chang et al., 1996; Guo et al., 2006). The main advantages of NTP technology compared to the conventional technologies include moderate operation conditions (normal temperature and atmospheric pressure), moderate capital cost, compact system, easy operations and short residence times, etc. (Nunez et al., 1993; Tonkyn et al., 1996; Ogata et al., 1999; Urashima et al., 2000 ; Park et al., 2003; Babel and Opiso, 2007; Subrahmanyam et al., 2007).

However, the major bottleneck of developing NTP with catalysis technology is the reduction of energy consumption. If this requirement is not satisfied, the nonthermal plasma process may lose its potential for commercial applications (Yamamoto et al., 1996; Tonkyn et al., 2003; Young et al., 2004). Many researcher found that for VOCs control, ferroelectric could improve energy efficiency significantly (Zhu et al., 2011), but ozone concentration increased due to ferroelectric presence (Yamamoto et al., 1992). Ogata et al. (2003) 
investigated the effects of alumina and metal ions in plasma discharge using NTP reactors packed with a mixture of $\mathrm{BaTiO}_{3}$ and porous $\mathrm{Al}_{2} \mathrm{O}_{3}$ pellets. The results indicated that the oxidative decomposition of benzene was enhanced by concentrating benzene on the $\mathrm{Al}_{2} \mathrm{O}_{3}$ pellets. The selected catalyst of $\mathrm{MnO}_{2}$ was well known for high potentials to decompose ozone (Van Durmea et al., 2007; Refaat, 2009). Futamura et al. (2004); Lee et al. (2011) and Refaat, (2011) tested catalytic effects of $\mathrm{TiO}_{2}$ and $\mathrm{MnO}_{2}$ with NTP. The results showed that the ozone generated from gaseous oxygen is decomposed by $\mathrm{MnO}_{2}$, but not by $\mathrm{TiO}_{2}$.

A series of experiments were performed for toluene decomposition from a gaseous influent at normal temperature and atmospheric pressure from 2005 to 2010 in Beijing. In this paper, the prepared nano$\mathrm{Ba}_{0.8} \mathrm{Sr}_{0.2} \mathrm{Zr}_{0.1} \mathrm{Ti}_{0.9} \mathrm{O}_{3}$ catalyst was used in the plasma reactor. Doped some ions ( $\mathrm{Sr}$ and $\mathrm{Zr}$ ) into the powder particles and crystal boundary in the experiment. The metal ions such as strontium, zinc and zirconium entered into crystal lattices of $\mathrm{BaTiO}_{3}$ equably and the Curie temperature $(\mathrm{Tc})$ fell. As a result, the permittivity of nano$\mathrm{Ba}_{0.8} \mathrm{Sr}_{0.2} \mathrm{Zr}_{0.1} \mathrm{Ti}_{0.9} \mathrm{O}_{3}$ was up to $10^{4}$ which were 12 times higher than that of pure $\mathrm{BaTiO}_{3}$, while dielectric loss reduced to $1 / 6$ in normal temperature. This study found that this nano-material could reduce the energy consumption and increase energy efficiency significantly.

The oxidative decomposition of benzene was enhanced by concentrating toluene on the $\mathrm{Al}_{2} \mathrm{O}_{3}$ pellets. The selected catalyst of $\mathrm{MnO}_{2}$ was well known for high potential to decompose ozone. In the experiment, the prepared $\mathrm{MnO}_{2} / \gamma-\mathrm{Al}_{2} \mathrm{O}_{3}$ was used as catalyst to reduce the byproducts and toluene concentrations (Zhu et al., $2009 \mathrm{~b}$ ) also justified about $10 \mathrm{wt} \%$. The objective of this study was to use a combination of catalysts $\left(\mathrm{MnO}_{2} / \gamma\right.$ $\mathrm{Al}_{2} \mathrm{O}_{3}$ coupled with modified ferroelectric of nano- $\mathrm{Ba}_{0.8}$ $\mathrm{Sr}_{0.2} \mathrm{Zr}_{0.1} \mathrm{Ti}_{0.9} \mathrm{O}_{3}$ ) in the NTP process for toluene decomposition in order to enhance toluene decomposition efficiency and increase energy efficiency and reduce byproducts for commercial applications.

\section{MATERIALS AND METHODS}

\section{Experimental setup}

The reaction system was a tube-wire packed bed reaction system at normal temperature and atmospheric pressure. The schematic diagram of the NTP system used in this investigation is shown in Fig. 1. Dry air (78.5 $\% \mathrm{~N}_{2}, 21.5 \% \mathrm{O}_{2}$ ) was used as a balance gas for toluene decomposition. Air supplied from an air compressor was divided into two air flows. Each flow rate was controlled with a mass flow meter. One air flow was introduced into a toluene liquid bottle (3) which contained liquid toluene. The air with a mass of saturated vapor of toluene was mixed with the other air flow in a blender (5) and the gaseous toluene was diluted to a prescribed concentration of $800 \sim 1000 \mathrm{mg} / \mathrm{m}^{3}$. A wire-tube Dielectric barrier discharge (DBD) reactor packed with catalyst was used to study the reaction as shown in Fig. 2.

An alternating current (AC) of $150 \mathrm{~Hz}$ was supplied to the NTP reactor in the radial direction, and the voltage extension changed from $0 \mathrm{kV}$ to $50 \mathrm{kV}$. The experimental parameters of the process of discharge were detected by an oscillograph (model TDS2014, manufactured by American Tektronix Co.). The primary power values

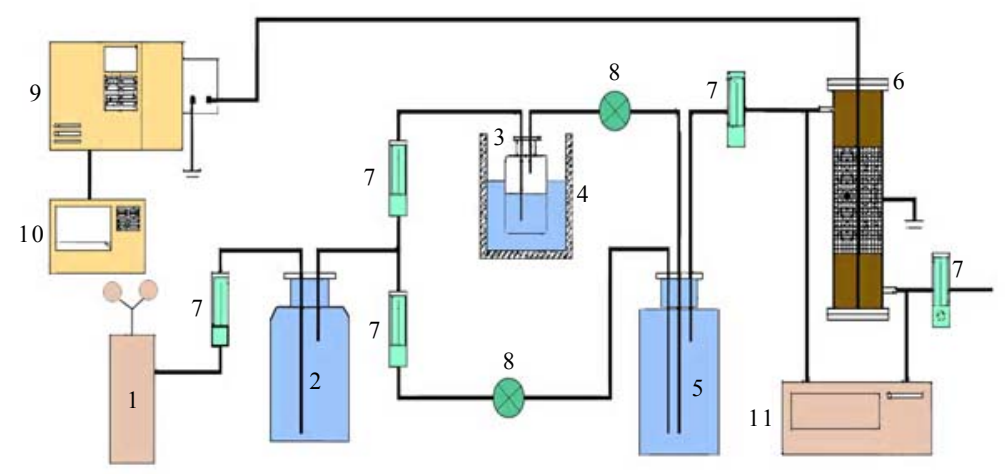

1. Air compressor 2. Buffer 3. Toluene liquid bottle 4. Attemperator 5. Blender 6. NTP reactor 7. Mass flow meter 8. Valve 9.High voltage 10 Oscillograph 11. Gas chromatography (GC)

Fig. 1: Schematic diagram of NTP system for toluene decomposition 


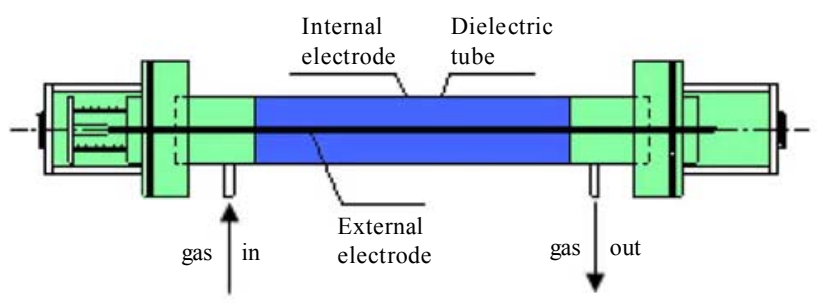

Reactor: Organic-glass tube (i.d.50 mm, length $150 \mathrm{~mm}$ ) Internal electrode: Tungsten filament (i.d.0.5 mm)

External electrode: Dense steel mesh

Fig. 2: NTP reactor

were measured with the voltage-charge (V-Q) Lissajous method in the plasma reactor.

Toluene decomposition was studied with a combination of catalysts including $\mathrm{MnO}_{2} / \gamma-\mathrm{Al}_{2} \mathrm{O}_{3}$ and nano- $\mathrm{Ba}_{0.8} \mathrm{Sr}_{0.2} \mathrm{Zr}_{0.1} \mathrm{Ti}_{0.9} \mathrm{O}_{3}$ catalysts (volume ratio of 1:1). The manganese oxide catalysts (5 wt \%, $10 \mathrm{wt} \%, 15 \mathrm{wt}$ $\%$ ) were prepared by impregnation of pellet type ${ }^{3}$-alumina with the granules diameter of 5 7 mm and BET surface area of $228 \mathrm{~m}^{2} / \mathrm{g}$ detected by Micromeritics (model NOVA 1000, manufactured by American Quantachrome Co.). Nanometer - sized $\mathrm{Ba}_{0.8} \mathrm{Sr}_{0.2} \mathrm{Zr}_{0.1} \mathrm{Ti}_{0.9} \mathrm{O}_{3}$ powders were prepared with inorganic salts, such as $\mathrm{TiCl}_{4}$ and $\mathrm{Ba}(\mathrm{OH})_{2}$, as the raw materials by a water-thermal method at normal pressure. Particulate diameters of $\mathrm{Ba}_{0.8} \mathrm{Sr}_{0.2} \mathrm{Zr}_{0.1} \mathrm{Ti}_{0.9} \mathrm{O}_{3}$ was $59 \mathrm{~nm}$ which was detected by XRD (model D8 ADVANCE, manufactured by Germany Bruker Co.) and BET surface area was $8.8 \mathrm{~m}^{2} / \mathrm{g}$. The relative permittivity of nano$\mathrm{Ba}_{0.8} \mathrm{Sr}_{0.2} \mathrm{Zr}_{0.1} \mathrm{Ti}_{0.9} \mathrm{O}_{3}$ was about $10^{4}$ (detected by inductance capacitance resistance (LCR) automatism test instrument 4210). The toluene concentration was determined using a gas chromatography (model HP6890N, manufactured by Agilent Co.) with a Flame ionization detector (FID) and a capillary column of HP-5 (internal diameter of $0.32 \mathrm{~mm}$, length $30 \mathrm{~m}$ ). The byproducts such as aldehyde, alcohols, amide, hydroxybenzene and polymerization products, etc, were identified by Gas chromatography mass spectrometry (GC-MS) (manufactured by American Thermo Finnegan Co.) and FT-IR (model Vertex 70, manufactured by Germany). Ozone concentration was measured by a chemical titration method of iodine (Zhu et al., 2009b).

\section{Evaluation criterion}

As evaluation criterion, the toluene removal efficiency, reactor energy density and energy efficiency in the gas phase were calculated as follows. Toluene removal efficiency (ç): $\eta(\%)=\frac{[\text { toluene }]_{\text {inlet }}-[\text { toluene }]_{\text {outlet }}}{[\text { toluene }]_{\text {inlet }}} \times 100 \%$

Reactor input energy density (RED):

$R E D(k J / L)=\frac{\text { input } \cdot \operatorname{power}(W)}{\text { gas } \cdot \text { flow } \cdot \operatorname{rate}(L / \mathrm{min})} \times 60 \times 10^{-3}$

Energy efficiency (æ) :

$\zeta(\mathrm{g} / \mathrm{kWh})=\frac{\left[\text { toluene }_{\text {inlet }} \times \eta\right.}{R E D} \times 3.6 \times 10^{-3}$

\section{RESULTS AND DISCUSSION}

Effect of combined catalysts on toluene removal efficiency

As the $\mathrm{MnO}_{2} / \gamma-\mathrm{Al}_{2} \mathrm{O}_{3}$ catalyst has the best effect for ozone decomposition but not for toluene decomposition (Delagrange et al., 2006) and nano$\mathrm{Ba}_{0.8} \mathrm{Sr}_{0.2} \mathrm{Zr}_{0.1} \mathrm{Ti}_{0.9} \mathrm{O}_{3}$, a type of developmental material on base of pure $\mathrm{BaTiO}_{3}$ (typical ferroelectric), enhances energy efficiency because of its higher relative permittivity of $10^{4}$ (Shi et al., 2008), a combination of nano- $\mathrm{Ba}_{0.8} \mathrm{Sr}_{0.2} \mathrm{Zr}_{0.1} \mathrm{Ti}_{0.9} \mathrm{O}_{3}$ with $\mathrm{MnO}_{2} / \gamma-\mathrm{Al}_{2} \mathrm{O}_{3}$ as a combined catalyst was tested in this study. The effect of various catalysts such as multiple catalyst, nano$\mathrm{Ba}_{0.8} \mathrm{Sr}_{0.2} \mathrm{Zr}_{0.1} \mathrm{Ti}_{0.9} \mathrm{O}_{3}, \mathrm{MnO}_{2} / \gamma-\mathrm{Al}_{2} \mathrm{O}_{3}$ and no padding on removal efficiency is shown in Fig. 3 (toluene concentration: $800-1000 \mathrm{mg} / \mathrm{m}^{3}$; gas flow rate: $2 \mathrm{~L} / \mathrm{min}$; AC frequency: $150 \mathrm{~Hz}$ ). The removal efficiency increased significantly with the catalysts than that without. The removal efficiency increased in the order of: combined catalyst $>$ nano- $\mathrm{Ba}_{0.8} \mathrm{Sr}_{0.2} \mathrm{Zr}_{0.1} \mathrm{Ti}_{0.9} \mathrm{O}_{3}>$ $\mathrm{MnO}_{2} / \gamma-\mathrm{Al}_{2} \mathrm{O}_{3}>$ no padding. The best removal efficiency of $98.7 \%$ was achieved in the NTP process. It indicated that the combination of catalysts exhibited a synergistic effect for toluene decomposition. 
Effect of combined catalysts on ozone formation

Fig. 4 shows the influence of various catalysts on ozone formation with the order of: combined catalyst $>$ $\mathrm{MnO}_{2} / \gamma-\mathrm{Al}_{2} \mathrm{O}_{3}>$ no padding $>$ nano- $\mathrm{Ba}_{0.8} \mathrm{Sr}_{0.2} \mathrm{Zr}_{0.1} \mathrm{Ti}_{0.9} \mathrm{O}_{3}$ at $\mathrm{RED}$ of $0.5 \mathrm{~kJ} / \mathrm{L}$. This result suggested that $\mathrm{MnO}_{2} / \gamma-$ $\mathrm{Al}_{2} \mathrm{O}_{3}$ in the combination of catalysts should have a main effect on ozone decomposition.

\section{Effect of the combination of catalysts on energy} efficiency

Fig. 5 shows the influence of various catalysts on energy efficiency with the order of: combined catalyst $>$ nano $\mathrm{Ba}_{0.8} \mathrm{Sr}_{0.2} \mathrm{Zr}_{0.1} \mathrm{Ti}_{0.9} \mathrm{O}_{3}>\mathrm{MnO}_{2} / \gamma-\mathrm{Al}_{2} \mathrm{O}_{3}>$ no padding at the same Specific discharge energy density (SED).These results indicated that the nano$\mathrm{Ba}_{0.8} \mathrm{Sr}_{0.2} \mathrm{Zr}_{0.1} \mathrm{Ti}_{0.9} \mathrm{O}_{3}$ in the combination of catalysts

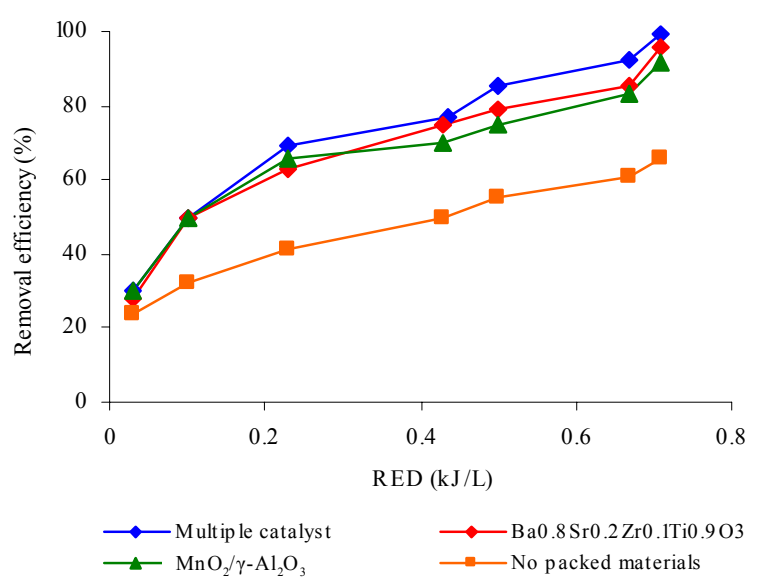

Fig. 3: The change of removal efficiency with various padding

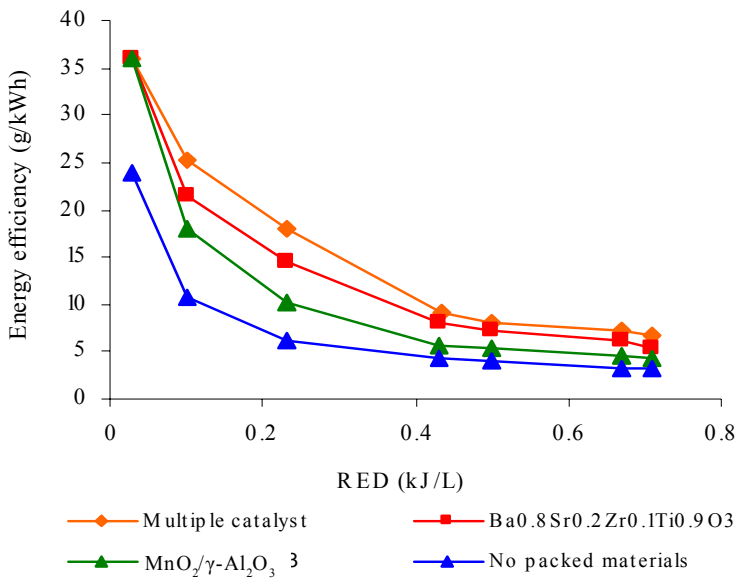

Fig. 5: The energy efficiency with various padding should play an important role for improving energy efficiency.

As a result, the combination of catalysts shows the best removal efficiency of toluene, the best decomposition effect of ozone and the best energy efficiency for toluene removal.

Byproducts and decomposition pathways of toluene

Non-thermal plasma has high potential in air cleaning technology, but in some cases unwanted byproducts are formed which could be more harmful than the original VOCs. Fig. 6 shows the FT-IR (Fourier transforms infrared spectrum) of the byproducts of toluene decomposition and Fig. 7 shows the FT-IR spectrum of the byproducts on the surface of the combination of catalysts.

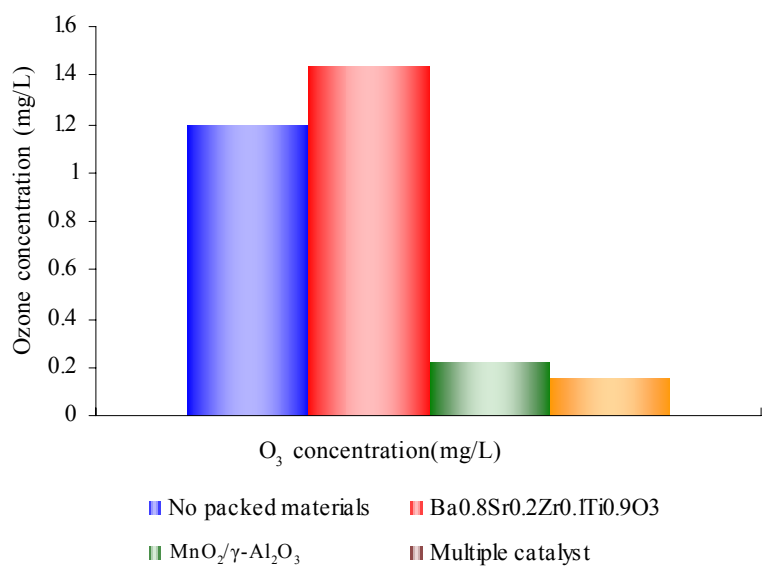

Fig. 4: The change of $\mathrm{O}_{3}$ concentration with various padding

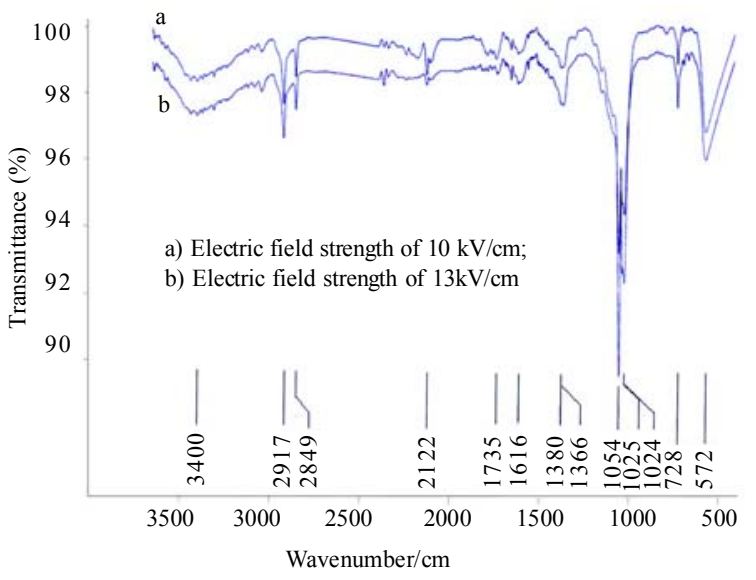

Fig. 6: FT-IR spectrum of the products from toluene decomposition 


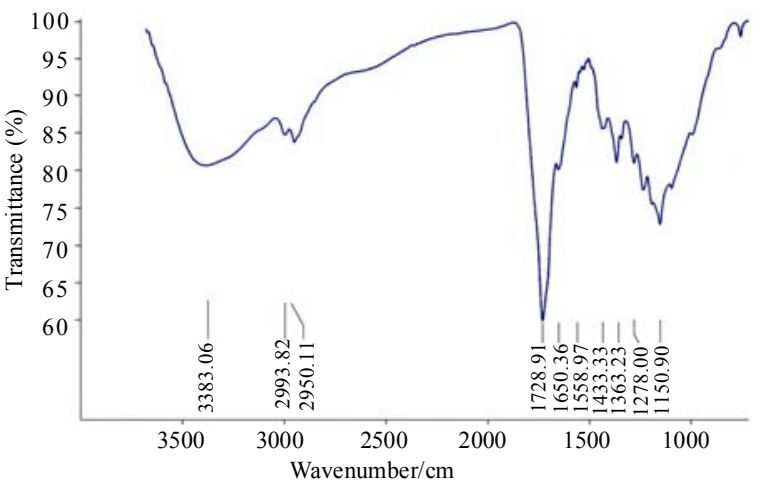

(a) Without catalyst in the NTP reactor

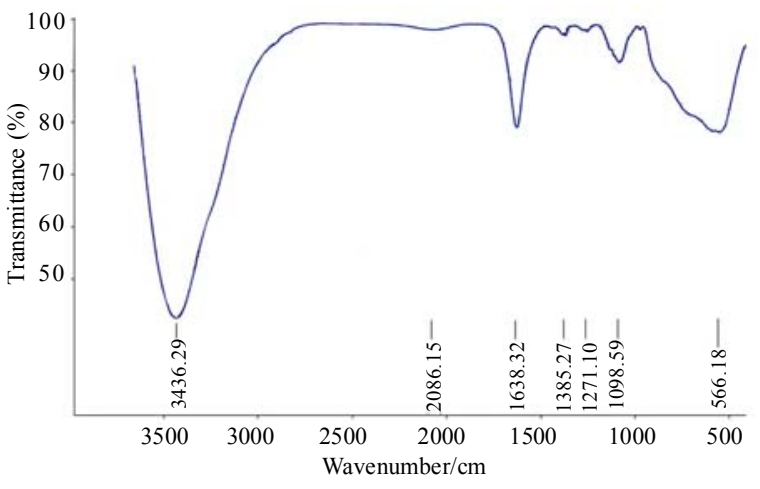

(b) With the combination of catalysts in the NTP reactor

Fig. 7: FT-IR spectrum of the byproducts on the surface of the combination of catalysts

As shown in Fig. 7a, the -NH- and $-\mathrm{NH}_{2}$ peak appeared at $3350 / \mathrm{cm}$ while the peak of $2730 / \mathrm{cm} \mathrm{N}=\mathrm{C}-\mathrm{N}$ was absent. The peak - NH- with benzene ring appeared at $3450 / \mathrm{cm},-\mathrm{OH}$ at $3400 / \mathrm{cm},-\mathrm{CH}_{3} /-\mathrm{CH}_{2}$ at $2900 / \mathrm{cm}$, benzene derivative (hydroxybenzene, polymerization products, etc) at $1700 \sim 1100 / \mathrm{cm}$, and $\mathrm{CO}_{2}$ and $\mathrm{CO}$ separately at the range of $2300 \sim 2100 / \mathrm{cm}$ and $700 \sim 500$ $\mathrm{cm}^{-1}$ respectively. Thus, the byproducts on the surface of the combination of catalysts involved aldehyde, alcohols, amide, and benzene derivative. However, when the combination of catalysts were packed into the NTP reactor, the byproducts on the surface of the packed materials in the NTP reactor reduced greatly as shown in Fig. 7b. Except of amine, $\mathrm{CO}_{2}$ and $\mathrm{CO}$, no other byproducts were detected on the surface of catalysts. It illuminated that the synergic effect of the NTP with the combination of catalysts could control byproducts effectively. In Fig. 6, the products of toluene decomposition included $\mathrm{CO}_{2}, \mathrm{CO}$ and $\mathrm{H}_{2} \mathrm{O}$. At the same time, there are a mass of ozone (strong peak at 1000/cm), and several amide and benzene derivatives. Compared spectrum ' $a$ ' with ' $b$ ' in Fig. 6, the benzene derivatives and ozone concentration reduce while the amounts of $\mathrm{CO}_{2}$ and $\mathrm{H}_{2} \mathrm{O}$ increase with the increase of the electric field strength. A large number of high-energy electrons, ions and free radicals were produced in the NTP reaction process. Firstly, the high-energy electrons could take part in reaction with oxygen in air as follow (Kim et al., 2008):

$\overrightarrow{\mathrm{e}}+\mathrm{O}_{2} \rightarrow \mathrm{e}+\mathrm{O}_{2}^{\bullet}\left(\mathrm{A}^{3} \sum_{u}^{+}\right) \rightarrow \mathrm{e}+\mathrm{O}\left({ }^{3} \mathrm{P}\right)+\mathrm{O}\left({ }^{3} \mathrm{P}\right)$

$\overrightarrow{\mathrm{e}}+\mathrm{O}_{2} \rightarrow \mathrm{e}+\left(\mathrm{B}^{3}\right) \rightarrow \mathrm{e}+\mathrm{O}\left({ }^{1} \mathrm{D}\right)+\mathrm{O}\left({ }^{3} \mathrm{P}\right)$

The oxygen free radical groups react with oxygen and other molecules to form ozone:
$\mathrm{O}+\mathrm{O}_{2}+\mathrm{M} \rightarrow \mathrm{O}_{3}^{\bullet}+\mathrm{M} \rightarrow \mathrm{O}_{3}+\mathrm{M}$

At the same time, the high-energy electrons react with $\mathrm{H}_{2} \mathrm{O}$ and $\mathrm{N}_{2}$ in gaseous phase:

$\mathrm{e}+\mathrm{H}_{2} \mathrm{O} \rightarrow \mathrm{OH}^{\cdot}+\mathrm{H}^{\cdot}$

$\mathrm{e}+\mathrm{H}_{2} \mathrm{O} \rightarrow 2 \mathrm{H}^{\bullet}+\mathrm{O}^{\bullet}$

$\mathrm{H}_{2} \mathrm{O}+\mathrm{O}\left({ }^{1} \mathrm{D}\right) \rightarrow 2 \mathrm{OH}^{\bullet}$

$\mathrm{e}+\mathrm{N}_{2} \rightarrow 2 \mathrm{~N}^{\cdot}$

Toluene bond energy between the carbon of benzene ring and the carbon of the substituent radical is $3.6 \mathrm{eV}$, which is lower than that of carboncarbon bond or hydrocarbon bond. As a hydrogen atom in a benzene ring is replaced by a methyl radical to form toluene, the newly formed bond is less stable and the most vulnerable. Of course, the other bonds are also likely to be destroyed by high energy electrons. Formulas 11 to 16 are the possible reaction equations of the process of toluene removal (Kohno et al., 1998).
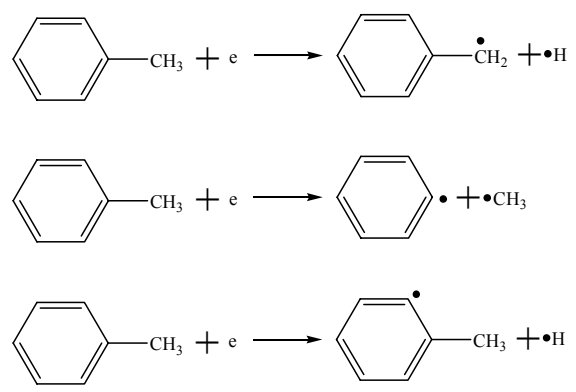


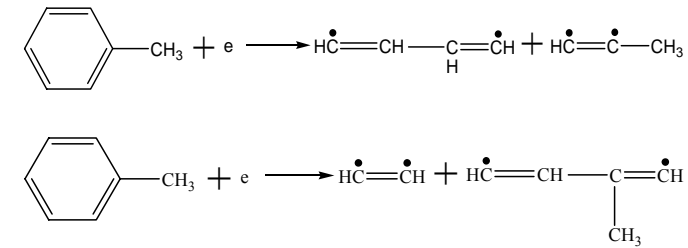

$\Longrightarrow-\mathrm{CH}_{3}+\mathrm{e} \stackrel{\geq 5.5 \mathrm{eV}}{\longrightarrow} \dot{\mathrm{CH}}_{2}-\underset{\mathrm{H}}{\mathrm{C}}=\underset{\mathrm{H}}{\mathrm{C}}-\underset{\mathrm{H}}{\mathrm{C}}=\underset{\mathrm{H}}{\mathrm{C}}-\dot{\mathrm{CH}}_{2}$

According to the FT-IR spectrums (Fig. 7), the author speculated the reaction pathways for toluene decomposition with the NTP and the combination of catalysts (Fig. 8). The oxygen and hydroxyl free radicals of should be the inducement during the process of toluene oxidation. The oxidation process of toluene may involve many reactions and these reactions cooperate and interact with each other for toluene decomposition. Firstly, a series of chain reactions take place between $\mathrm{OH}$ radicals and toluene molecules due to the higher oxidation ability of $\mathrm{OH}$ radicals than that of oxygen radicals:

$\longrightarrow \mathrm{CH}_{3}+\mathrm{OH} \longrightarrow+\mathrm{H}_{2} \mathrm{O}+\mathrm{CH}_{2}^{\circ}$

$+\mathrm{OH}^{*} \longrightarrow$

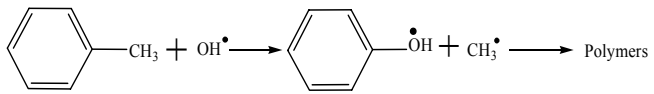

Then, the idiographic reactions occur because of oxygen free radicals during the subsequent oxidation reaction as follows:

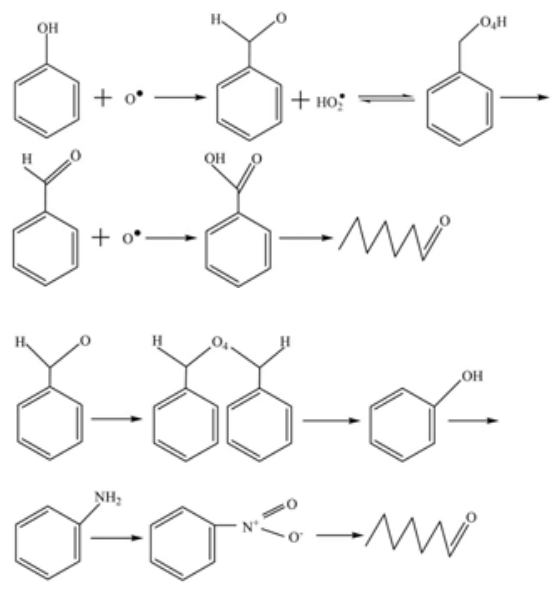

The binding bonds inside the benzene ring break down after the bonds outside the benzene ring break as follows:
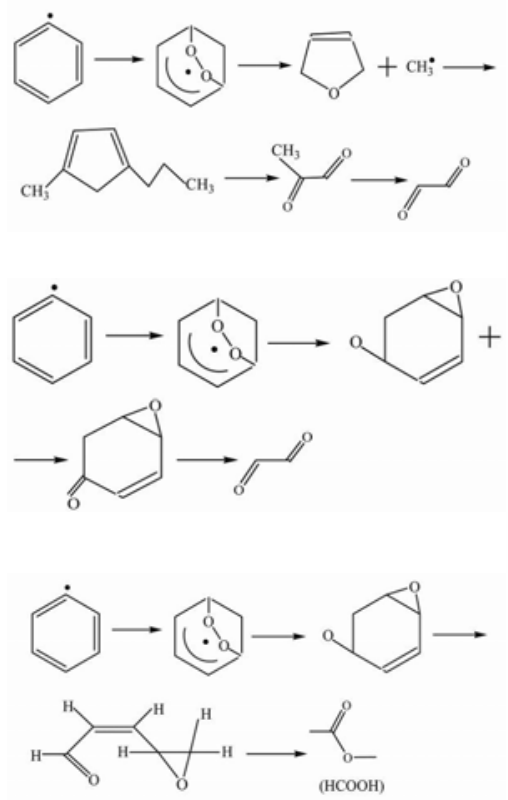

At last, the byproducts were oxidized to $\mathrm{CO}_{2}$ and $\mathrm{H}_{2} \mathrm{O}$ with increasing RED and the help of catalysis. At last, the byproducts were oxidized to $\mathrm{CO}_{2}$ and $\mathrm{H}_{2} \mathrm{O}$ with increasing RED and the help of catalysis.

$\bigwedge^{\mathrm{O}} \longrightarrow \mathrm{CO}+\mathrm{O} \cdot \longrightarrow \mathrm{CO}_{2}$

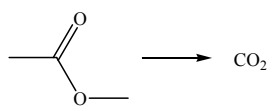<smiles>CC(C)(C)C(=O)C=O</smiles>

Perry et al. (1977) reported that aromatic compounds react with $\mathrm{OH}$ radicals by two pathways: hydrogen atom abstraction and $\mathrm{OH}$ addition to the aromatic ring. Reaction control pathways I-XII were illustrated in Fig. 8. The results showed in a complex oxidation mechanism of toluene via several pathways, producing either ring-retaining or ring-opening products. The final products were $\mathrm{CO}_{2}$ and $\mathrm{H}_{2} \mathrm{O}$.

The synergistic effect of the combination of catalysts with the NTP reactor is presented in Fig. 9. 
The catalyst carrier of $\gamma-\mathrm{Al}_{2} \mathrm{O}_{3}$ possesses sorbent characteristic, thus it could improve toluene concentration on the catalyst surface and increase the reaction time. $\mathrm{MnO}_{2}$ is known as a metal oxide catalyst and has been reported to possess a potential activity in redox reactions. $\mathrm{MnO}_{2}$ surface has been found to expose metal $\left(\mathrm{Mn}^{\mathrm{n}+}\right)$, oxide $\left(\mathrm{O}^{2-}\right)$ and defect sites of various oxidation states, present degrees of coordination instauration, and exhibit acid and base properties.
Furthermore, the $\mathrm{d}-\mathrm{d}$ electrons exchange interactions between intimately coupled manganese ions of different oxidation states $\left[\mathrm{Mn}^{\mathrm{n}+}-\mathrm{O}-\mathrm{Mn}^{(\mathrm{n}+1)+}\right]$ furnish the electron-mobile environment necessary for the surface redox activity (Zhu et al., 2009b):

$$
\begin{aligned}
& \mathrm{O}_{3}+\mathrm{Mn}^{\mathrm{n}+} \rightarrow \mathrm{O}_{2}^{2-}+\mathrm{Mn}^{(\mathrm{n}+2)+}+\mathrm{O}_{2} \\
& \mathrm{O}_{3}+\mathrm{O}^{2-}+\mathrm{Mn}^{(\mathrm{n}+2)+} \rightarrow \mathrm{O}_{2}^{2-}+\mathrm{Mn}^{(\mathrm{n}+2)+}+\mathrm{O}_{2}
\end{aligned}
$$

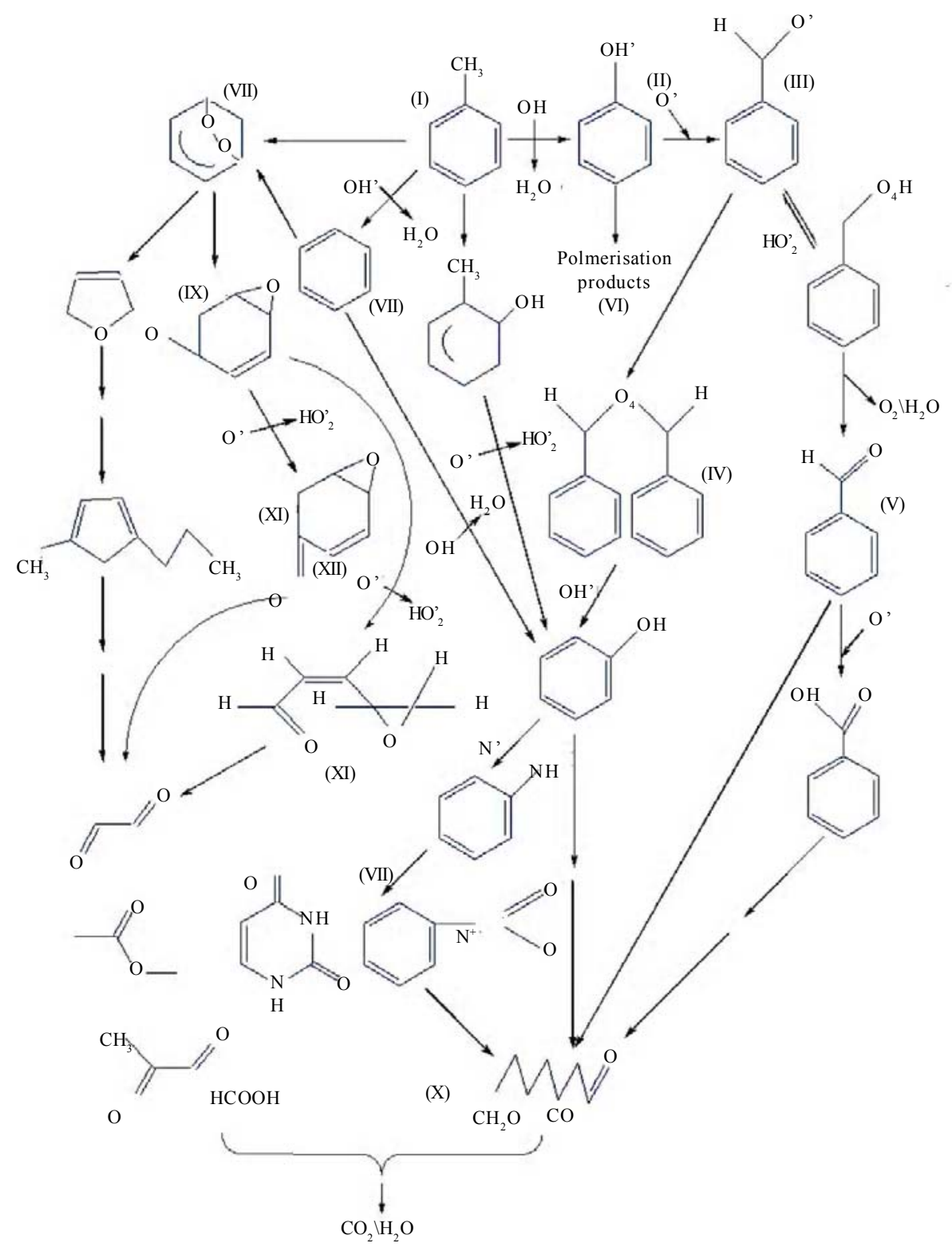

Fig. 8: Abatement pathways of toluene by NTP with the combination of catalysts 


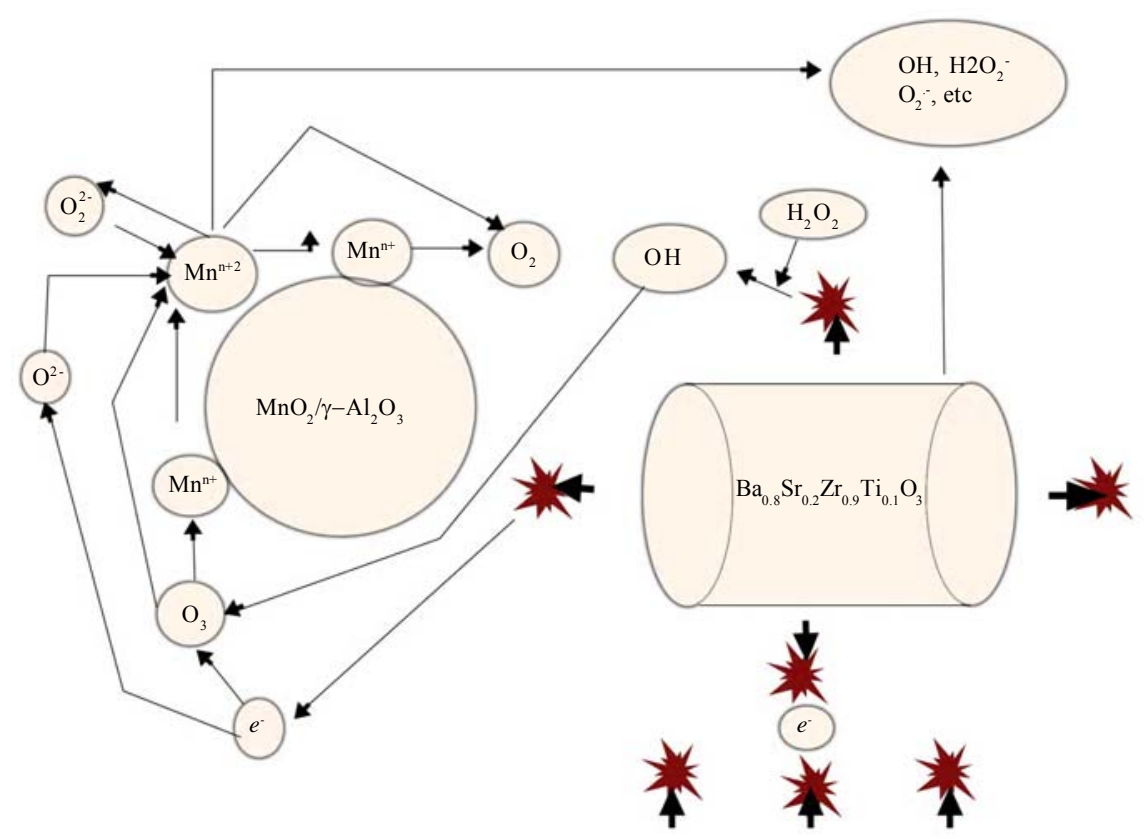

Fig. 9: Catalysis chart of the combination of catalysts in the process of gas discharge

$$
\mathrm{O}_{2}^{2-}+\mathrm{Mn}^{(\mathrm{n}+2)+} \rightarrow \mathrm{Mn}^{\mathrm{n}+}+\mathrm{O}_{2}
$$

These factors would be helpful for toluene decomposition. Radhakrishnan (2001) reported that ozone decomposed to $\mathrm{O}^{2-}$ and $\mathrm{O}_{2}^{2-}$ in the surface of $\mathrm{MnO}_{2}$. Naydenov et al. (1993) believed that $\mathrm{O}^{-}$existed in the surface of $\mathrm{MnO}_{2}$ according to the oxidation of benzene in the surface of $\mathrm{MnO}_{2}$. As a modified ferroelectric, nano- $\mathrm{Ba}_{0.8} \mathrm{Sr}_{0.2} \mathrm{Zr}_{0.1} \mathrm{Ti}_{0.9} \mathrm{O}_{3}$ has a higher dielectric constant than $\mathrm{BaTiO}_{3}$ and is polarized at lower electric field strength. More high energy electrons and active radicals are generated to accelerate the reaction between NTP and toluene molecules.

\section{CONCLUSION}

Series of experiments were performed for removal of toluene gaseous influent at normal temperature and atmospheric pressure. In this study, the prepared combined catalyst was used to improve the NTP process and to take the catalytic advantages of both $\mathrm{MnO}_{2} / \gamma-\mathrm{Al}_{2} \mathrm{O}_{3}$ and nano- $\mathrm{Ba}_{0.8} \mathrm{Sr}_{0.2} \mathrm{Zr}_{0.1} \mathrm{Ti}_{0.9} \mathrm{O}_{3}$. From the view of materials application, the authors adopted NTP coupled with the combination of catalysts technology to decompose VOCs in this study. The catalyst materials could be prepared easily and inexpensing, and at the same time, this combined technology resolved the key bottlenecks effectively. Therefore, the combination of catalysts technology could advance to the NTP technology and improve applications in the industry in the future.

\section{ACKNOWLEDGEMENTS}

This work was supported by the Youth Research Funding of China University of Mining and Technology (Beijing) and the Fundamental Research Funds for the Central Universities (2009QH03), Public Welfare Project of China Environmental Protection Department (201009052-02) and National $863 \mathrm{key}$ project (2009AA 063201).

\section{REFERENCES}

Babel, S., Opiso, E.M., (2007). Removal of Cr from synthetic wastewater by sorption into volcanic ash soil. Int. J. Environ. Sci. Tech., 4 (1), 99-107 (9 pages).

Chang, M. B.; Balbach, J. H.; Rood; M. J.; Kushner, M. J., (1991). Removal of $\mathrm{SO}_{2}$ from gas streams using a dielectric barrier discharge and combined plasma photolysis. J. Appl. Phys., 69 (8), 4409-4418 (10 pages).

Chang, M. B.; Tseng, T. D., (1996). Gas-phase removal of $\mathrm{H}_{2} \mathrm{~S}$ and $\mathrm{NH}_{3}$ with dielectric barrier discharges. J. Environ. Eng., 122 (1), 41-46 (6 pages). 
Delagrange, S.; Pinard, L.; Tatibouet, J. M., (2006). Combination of a non-thermal plasma and a catalyst for toluene removal from air: Manganese based oxide catalysts. Appl. Catal. B: Environ., 68 (3-4), 92-98 (7 pages).

Futamura, S.; Zhang, A. H.; Yamamoto, T., (1997). The dependence of nonthermal plasma behavior of VOCs on their chemical structures. J. Electrostat., 42 (1-2), 51-62 (12 pages).

Futamura, S.; Einaga, H.; Kabashima, H., (2004). Synergistic effect of silent discharge plasma and catalysts on benzene decomposition. Catal., Today, 89 (1-2), 89-95 (7 pages).

Gal, A.; Ogata, A.; Futamura, S., (2003). Mechanism of the dissociation of chlorofluorocarbons during nonthermal plasma processing in nitrogen at atmospheric pressure. J. Phys. Chem. A., 107 (42), 8859-8866 (8 pages).

Guo, Y. F.; Ye, D. Q.; Chen, K. F., (2006). Toluene decomposition using a wire-plate dielectric barrier discharge reactor with manganese oxide catalyst in situ. J. Molecular. Cata. A: Chem., 245 (1-2), 93-100 (8 pages).

Juang, D. F.; Lee, C. H., Hsueh, S. C., (2009a). Chlorinated volatile organic compounds found near the water surface of heavily polluted rivers. Int. J. Environ. Sci. Tech., 6 (4), 545-556 (12 pages).

Juang, D. F.; Yuan, C. S.; Hsueh, S. C.; Chiou, L. J., (2009b). Distribution of volatile organic compounds around a polluted river. Int. J. Environ. Sci. Tech., 6 (1), 91-104 (14 pages).

Kim, H. H., (2006). Effect of different catalysts on the decomposition of VOCs using flow-type plasma-driven catalysis. IEEE. Trans. Plasma. Sci., 34 (3), 984-995 (12 pages).

Kim, H. H.; Ogata, A.; Futamura, S., (2008). Oxygen partial pressure-dependent behavior of various catalysts for the total oxidation of VOCs using cycled system of adsorption and oxygen plasma. Appl. Catal. B: Environ., 79 (4), 356367 (12 pages).

Kohno, H.; Berezin, A. A.; Chang, J. S., (1998). Destruction of volatile organic compounds used in a semiconductor industry by a capillary tube discharge reactor. IEEE. Trans. Ind. Appl., 34 (5), 953-966 (14 pages).

Lee, K.; Lee, E.; Lee, H.; Kim, Y. K.; Sohn, K., (2011). Hydrogen peroxide interference in chemical oxygen demand during ozone based advanced oxidation of anaerobically digested livestock wastewater. Int. J. Environ. Sci. Tech., 8 (2), 381-388 (8 pages)

Magureanu, M.; Mandache, N. B.; Hu, J. C.; Richards, R.; Florea, M.; Parvulescu, V. I., (2005). Plasma-assisted catalysis for volatile organic compounds abatement. Appli. Cata. B: Environ., 61 (1-2), 12-20 (9 pages).

Magureanu, M.; Mandache; N. B.; Parvulescu, V. I.; Subrahmanyam, C.; Renken, A.; Kiwi Minsker, L., (2007). Improved performance of non-thermal plasma reactor during decomposition of trichloroethylene: Optimization of the reactor geometry and introduction of catalytic electrode. Appl. Catal. B: Environ., 74 (3-4), 270-277 (8 pages).

Malik, M. A.; Minamitani, Y.; Schoenbach, K. H., (2005). Comparison of catalytic activity of aluminum oxide and silica gel for decomposition of volatile organic compounds (VOCs) in a plasmacatalytic reactor. IEEE. Trans. Plasma. Sci., 33 (1), 50-56 (7 pages).

Masuda, S., (1988). Pulse corona induced plasma chemical process: a horizon of new plasma chemical technologies. Pure. Appl. Chem., 60 (5), 727-731 (5 pages).
Mizuno, A. ; Clements, J. S. ; Davis. R. H., (1986). A method for the removal of sulfur dioxide from exhaust gas utilizing pulsed streamer corona for electron energization. IEEE. Trans. Ind. Appl., 22 (3), 516-522 (7 pages).

Muhamad. A. M.; Jiang. X. Z., (2000). Catalyst assisted destruction of trichloro ethylene and toluene in corona discharges. J. Environ. Sci., 12 (1), 7-11 (5 pages).

Naydenov, A.; Mehandjiev. D., (1993). Complete oxidation of benzene on manganese dioxide by ozone. App1.Cata1. A: Gen., 97 (1), 17-22 (6 pages).

Nunez, C. M.; Ramsey. G. H.; Ponder, W. H.; Abbott, J. H.; Hamel, L. E.; Kariher, P. H., (1993). Corona destruction: An innovative control technology for VOCs and air toxics. Air. Waste., 43 (2), 242-247 (6 pages).

Ogata, A.; Einaga, H.; Kabashima, H., (2003). Effective combination of nonthermal plasma and catalysts for decomposition of benzene in air. Appl. Catal. B: Environ., 46 (1), 87-95 (9 pages).

Ogata, A.; Yamanonchi, K.; Mizuno, K., (1999). Decomposition of benzene using alumina-hybrid and catalyst-hybrid plasma reactors. IEEE. Trans. Ind. Appl., 35 (6), 1289-1295 (7 pages).

Park, J. Y.; Jung, J. G.; Kim, J. S., (2003). Effect of nonthermal plasma reactor for CF decomposition. IEEE. Trans. Plasma. Sci., 31 (6), 1349-1354 (6 pages).

Perry, R. A.; Atkinson, R.; Pitts, J. N., (1977). Kinetics and mechanism of the gas phase reaction of hydroxyl radicals with aromatic hydrocarbons over the temperature range 296-473 K. J. Phys. Chem., 81 (4), 296-304 (9 pages).

Radhakrishnan, R.; Oyama, S. T.; Chen, J. G., (2001). Electron transfer effects in ozone decomposition on supported manganese oxide. J. Phys. Chem. B., 105 (19), 4245-4253 (9 pages).

Refaat, A. A. (2009). Correlation between the chemical structure of biodiesel and its physical properties. Int. J. Environ. Sci.Tech., 6 (4), 677-694 (8 pages).

Refaat, A. A., (2011). Biodiesel production using solid metal oxide catalysts. Int. J. Environ. Sci. Tech., 8 (1), 203-221 (19 pages).

Shi, A. H., Yan, W. B., Li, Y. J.; Huang, K. L., (2008). Preparation and characterization of nanometer-sized barium titanate powder by complex-precursor method. J.Centr. South Univ. Tech., 15 (3), 224-228 (5 pages).

Subrahmanyam, C.; Renken, A.; Kiwi-Minsker, L., (2007). Novel catalytic non-thermal plasma reactor for the abatement of VOCs. Chem. Eng. J., 134 (1-3), 78-83 (6 pages).

Tonkyn, R. G.; Barlow, S. E.; Orlando, T. M., (1996). Destruction of carbon tetrachloride in a dielectric barrier/ packed-bed corona reactor. J. Appl. Phys., 80 (9), 4877 4886 (10 pages).

Tonkyn, R. G.; Barlow, S. E.; Hoard, J., (2003). Reduction of NOx in synthetic diesel exhaust via two-step plasmacatalytic treatment. Appl. Catal. B. Environ., 40 (3), 207217 (11 pages).

Urashima, K.; Chang, J., (2000). Removal of volatile organic compounds from air streams and industrial flue gases by non-thermal plasma technology. IEEE. Trans. Dielectr. Electr. Insul., 7 (5), 602-614 (13 pages).

Van Durmea, J.; Dewulfa, J.; Sysmansa, W.; Leysb, C.; Van Langenhove, H., (2007). Efficient toluene abatement in 
indoor air by a plasma catalytic hybrid system. Appl. Cata. B: Environ., 74 (1-2), 161-166 (6 pages).

Yamamoto, T.; Ramanatiran, K.; Lawless, P. A.; Ensor, D. S.; Nwesome, J. R.; Plaks, N.; Ramsey, G. H., (1992). Control of Volatile organic compound by ac energized ferroelectric pellet reactor and a pulsed corona reactor. IEEE Trans. Ind. Appl., 28 (3), 528-533 (6 pages).

Yamamoto, T.; Mizuno, K.; Tamori, I.; Ogata, A.; Nifuku, M.; Michalska, M.; Prieto, G., (1996). Catalysis-assisted plasma technology for carbon tetrachloride destruction. IEEE. Trans. Ind. Appl., 32(1), 100-106 (7 pages).

Young, S. M.; Dors, M.; Jerzy, M., (2004). Effect of reaction temperature on NOx removal and formation of ammonium nitrate in nonthermal plasma process combined with selective catalytic reduction. IEEE. Trans. Plasma. Sci., 32 (1), 799807 (9 pages).

Zhu, T.; Li, J.; Jin, Y. Q.; Liang, Y. H.; Ma, G. D., (2009a). Gaseous phase benzene decomposition by nonthermal plasma coupled with nano-titania catalyst. Int. J. Environ. Sci. Tech., 6 (1), 141-152 (12 pages).

Zhu, T. ; Li, J. ; Liang, W. J.; Jin, Y. Q., (2009b). Synergistic effect of catalyst for oxidation removal of toluene. J. Hazard. Mater., 165, 1258-1261 (4 pages).

Zhu, T.; Wan, Y. D.; He, X. W.; Xu, D. Y.; Shu, X. Q., (2011). Effect of modified ferroelectric on nonthermal plasma process for toluene decomposition. Fresen. Environ. Bull., 20 (1), 149-155 (7 pages)

\section{AUTHOR (S) BIOSKETCHES}

Zhu, T., Ph.D., School of Chemical and Environmental Engineering, China University of Mining and Technology, Ding No.11, Xueyuan Rode, Haidian District, Beijing 100083, China. Email: bamboozt@cumtb.edu.cn

Wan, Y. D., M.Sc., School of Chemical and Environmental Engineering, China University of Mining and Technology, Ding No.11, Xueyuan Rode, Haidian District, Beijing 100083, China. Email: bamboozt@sohu.com

Li, J., Ph.D., Professor, College of Environmental and Energy Engineering, Beijing University of Technology, 100\# Ping Leyuan, Chaoyang District, Beijing 100124, China. E-mail: ljian@bjtu.edu.cn

He, X. W., Ph.D., Professor, School of Chemical and Environmental Engineering, China University of Mining and Technology. Ding No.11, Xueyuan Rode, Haidian District, Beijing 100083, China. Email: hjinghua@vip.sina.com

Xu, D. Y., Ph.D., Professor, School of Chemical and Environmental Engineering, China University of Mining and Technology, Ding No.11, Xueyuan Rode, Haidian District, Beijing 100083, China. Email: xudongyao101@163.com

Shu, X. Q., Ph.D., Professor, School of Chemical and Environmental Engineering, China University of Mining and Technology, Ding No.11, Xueyuan Rode, Haidian District, Beijing 100083, China. Email: xqshu@cumtb.edu.cn

Liang, W. J., Ph.D., Associate Professor, College of Environmental and Energy Engineering, Beijing University of Technology. 100\# Ping Leyuan, Chaoyang District, Beijing 100124, China. Email: lwj@bjut.edu.cn

Jin, Y. Q., Ph.D., Professor, College of Environmental and Energy Engineering, Beijing University of Technology. 100\# Ping Leyuan, Chaoyang District, Beijing 100124, China. Email: jyq@bjut.edu.cn

How to cite this article: (Harvard style)

Zhu, T.; Wan, Y. D.; Li, J.; He, X. W.; Xu, D. Y.; Shu, X. Q.; Liang, W. J.; Jin, Y. Q., (2011). Volatile organic compounds decomposition using non-thermal plasma coupled with a combination of catalysts. Int. J. Environ. Sci. Tech., 8 (3), 621-630. 